Aliran Eksistensialisme dalam Pandangan Filsafat Pendidikan Islam

Rabiatul Adawiah

Madrasah dan Transformasi Intelektual Muhdi

Kisah Keluarga Teladan dalam Al-Qur'an (Inspirasi Membangun Negara yang Thayyibah) Rahmat Sholihin

Tasawuf dalam Pandangan Nurcholish Madjid Ilham Masykuri Hamdie dalam Buku The Tao of Islam) Erni Susilawati

Islam, Keindonesiaan, dan Kemanusiaan

(Telaah Pemikiran Ahmad Syafii Maarif) Damanhuri

Pandangan Kritis Islam Liberal atas Isu-Isu Kontemporer Muhammad Taufik 


\section{AL - BANJARI \\ Jurnal Ilmiah Ilmu-Ilmu Keislaman}

Vol. 14, No. 1, Januari-Juni 2015

\section{DAFTAR ISI}

Aliran Eksistensialisme dalam Pandangan Filsafat Pendidikan Islam

Rabiatul Adawiah

Madrasah dan Transformasi Intelektual

Muhdi

Kisah Keluarga Teladan dalam Al-Qur'an (Inspirasi Membangun

Negara yang Thoyyibah)

Rahmat Sholihin

Tasawuf dalam Pandangan Nurcholish Madjid

Ilham Masykuri Hamdie

Psikologi Sufistik (Studi atas Pemikiran Sachiko Murata dalam Buku

The Tao of Islam)

60-75

Erni Susilawati

Islam, Keindonesiaan, dan Kemanusiaan (Telaah Pemikiran

Ahmad Syafii Maarif)

$76-84$

Damanhuri

Pandangan Kritis Islam Liberal atas Isu-Isu Kontemporer

85-105

Muhammad Taufik 


\title{
PSIKOLOGI SUFISTIK
}

\author{
(Studi atas Pemikiran Sachiko Murata dalam Buku The Tao of Islam)
}

\author{
Erni Susilawati \\ Dosen Tetap STIKIP PGRI Banjarmasin \\ E-mail: ernisusilawati96@yahoo.co.id (085248362821)
}

\begin{abstract}
Sachiko Murata has developed many discourses of spiritual psychology as mentioned in her book The Tao of Islam. The writer found that the highest stage of Sufi which is to be united with God exists vertically between the spirit, soul, mind and heart. Spirit is described as the highest inner dimension, which is connected to soul, as a part of the physical or body structure. The relationship between the soul and spirit raises other inner dimension that is the mind and heart. For a Sufi who has reached perfection or sanctity of life, it also means to have a harmonious relationship between man's inner dimension, namely the achievement of happiness and peace of mind which is reflected in real behavior. This is what Murata stated about a healthy soul, a soul which is strongly influenced by the spirit or goodness.
\end{abstract}

Keywords: Spiritual psychology, Sachiko Murata, man's inner dimension

\section{Pendahuluan}

Dalam Islam kajian mengenai hakekat jiwa sudah dibahas secara mendalam dan sistematis oleh para ulama ataupun ilmuwan Islam seperti Al-ghazali, Ibnu Sina, dan lain-lain sejak abad ke-9 Masehi. Hanya saja kajian hakekat jiwa dalam Islam tidak mendapat perhatian atau diabaikan oleh sejarah psikologi barat, karena dianggap tidak masuk dalam kajian psikologi fersi barat. Dalam psikologi barat hanya mengkaji gejala-gejala jiwa secara fisik melalui tingkah laku manusia.

Islamisasi ilmu pengetahuan mendorong kajian psikologi Agama dan Kesehatan Mentalmengalami Shifting Paradigm. Ketika psikologi agama dan kesehatan mental masuk dalamruang Islamisasi, keduanya semakin intensifberdialog dengan ajaran agama dan psikologi secara menyeluruh yang mencakup aqidah, syariat, danakhlak (tasawuf). Dampaknya, psikologi agama tidak hanya menggunakan paradigma epistimologi humanistik yang cenderung materialistik-ateis, melainkan juga menggunakan paradigma epistimologi meta-empirik, epistimologi spiritual. Kesehatan mental bersama psikologi Agama secara bersinergi mulai mendiskusikan dan melibatkan pengaruhajaran Islam, termasuk ajaran sufistik, terhadaporang yang meyakininya dalam pengembangan studinya. 
Tasawuf adalah dimensi lain dalam ajaran Islam yang mulai banyak menarik perhatian tidak saja bagi peneliti muslim maupun kaum orientalis tetapi juga sudah menarik perhatian bagi masyarakat awam. Tasawuf merupakan pendidikan mental dengan cara menguasai atau mengendalikan penyebab utama yang dapat menjerumuskan manusia ke dalam kehinaan, yaitu hawa nafsu dalam mengejar kehidupan material yang merupakan sumber utama dari kerusakan moral dan kehancuran umat manusia.

Jadi dapat dikatakan bahwa ajaran tasawuf mampu membimbing manusia menjadi hamba Allah yang membawa kedamaian dan mengandalikannya agar tidak terjadi mala petaka bagi dirinya dan alam sekitarnya. ${ }^{1}$ Untuk itu psikologi yang notabene merupakan studi kejiwaan sangat relevan dengan kajian tasawuf yang juga membahas masalah-masalah yang berkenaan dengan jiwa, nafs, ruh dan berupaya untuk menguak hakekat jiwa secara sufistik dan untuk melatih jiwa (nafs) menjadi jiwa yang siap menerima limpahan cahaya ilahi serta menjauhkannya dari pengaruh jasmani yang cenderung hedonisme melalui penyucian dan latihan-latihan pengendalian diri secara bertahab yang dalam istilah tasawuf tahapan-tahapan ini disebut maqom atau tingkatan yang harus dilalui bagi para sufi untuk bisa menjapai tahapan yang tertinggi, yakni kesempurnaan jiwa.

Untuk itu penulis merasa penting untuk mengkaji mengenai psikologi sufiistik yang banyak diabaikan bahkan oleh pemerhati psikologi muslim sendiri. Para psikologi muslim lebih cenderung berkiblat pada psikologi barat yang justru dalam pembahasan psikologinya belum menyentuh inti jiwa manusia, bahkan mereka cenderung pada kajian fisik. Hal ini sebagaimana dikatakan oleh Lynn Wilcox bahwa, psikologi membatasi dirinya hanya pada manefestasi-manefestasi fisik, sebaliknya tasawuf memasukan manefestasi-manefestasi fisik dalam visi tentang manusia yang lebih luas.

Dengan adanya pemikiran tersebut mungkin tidak mengejutkan jika sebuah pendekatan mistik tentang ilmu jiwa dalam Islam datang dari seorang wanita jepang yang bernama Sachiko Murata yang begitu bersimpatik terhadap Islam. Ia mencoba membedah aspek yang sering dianggap tidak penting yaitu kajian sisi bathiniah manusia dengan memakai kaca mata sufiistik.

Menurutnya, dalam bidang kajian tasawuf, penekanan utamanya adalah jiwa. Menurut para sufi pada awalnya jiwa memiliki sedikit persamaan dengan ruh yang merupakan nafas Tuhan. Karena jiwa merupakan bentuk ketidaksempurnaan seringkali alpa yang secara mistis diwakili oleh sisi negatif. Wahyu muncul sebagai suatu pesan dari Tuhan, dan begitu menerima pesan, jiwa masuk ke dalam jalan panjang perjuangan (mujâhadah atau jihad) melawan kecenderungan-kecenderungan negatif jiwa. ${ }^{2}$

Kondisi normal bagi jiwa adalah siap menerima cahaya yang datang dari ruh. Dengan begitu jiwa manjadi bercahaya dan berubah menjadi suatu zat ruhani. Jiwa naik dari dunia kegelapan menuju dunia cahaya. Kecenderungan turun yang selalu sering tampil merupakan akibat dari ketidakmampuan jiwa melihat cahaya, ketiadaan penerimaanya atas apa yang ada di luar dirinya, kepuasan dengan keterbatasannya

\footnotetext{
1 Asmaran AS., Pengantar Studi Tasawnf, (Jakarta; PT. Raja Grafindo Persada, 2002), cet. Ke 2, h. 10.

2 Ibid, 325
} 
sendiri, atau akibat tipu daya syetan. ${ }^{3}$

Dalam bukunya yang berjudul The Tao of Islam: A Sourcebook on Gender Relationship in Islamic Thought Murata mencoba membedah aspek-aspek feminitas dan kesetaraan gender dari kaca mata teologi dan juga mengkaji aspek psikologi ruhani sufistik. BukuterbitanState Universiti of New York Press pada tahun 1992 ini memuat ide-ide Sachiko Murata tentang Teologi Islam, Kosmologi dan Psikologi Sufistik. Gambaran singkat mengenai buku tersebut bisa dibagi dalam empat bagian. Bagian pertama Murata berbicara mengenai tiga realitas yaitu, Allah, Mikrokosmos atau makrokosmos dan manusia yang merupakan hubungan segi tiga dan Allah menjadi puncak sebagai sumber dari segala realitas.

Bagian yang kedua Murata bicara teologi, bahwa Tuhan sebagai dirinya sendiri maka Dia tak akan dikenal namun melalui keserupaan maka Dia dikenal melalui nama dan sifat-sifat-Nya. Dalam hal ini nama dan sifat-sifat Allah memiliki keseimbangan atau dualisme sebagaimana akan termanefestasi dalam ciptaan-Nya feminim dan maskulin.

Bagian ketiga dalam bukunya Murata membicarakan mengenai kosmos, dimana dia menganalogikan bumi sebagai jiwa feminim yang menerima, sedangkan langit sebagai jiwa maskulin yang cenderung memberi. Langit dan bumi adalah merupakan hubungan gender yang saling melengkapi satu dengan yang lainnya dan ini adalah merupakan manefestasi dari nama dan sifat-sifat Allah.

Bagian keempat inilah Murata berbicara jiwa atau psikologi ruhani, ia menggambarkan jiwa sebagai yang selalu memiliki dinamika sehingga jiwa dituntut untuk selalu berjuang melawan kecenderungan jiwa yang negatif untuk selalu bisa menerima cahaya dari ruh.

\section{Pemikiran Psikologi Ruhani Sachiko Murata dalam Buku: The Tao Of Islam Riwayat Hidup \& Karya Sachiko Murata Riwayat Hidup}

Sachiko Murata lahir di Jepang pada tahun 1945. Menyelesaikan kuliah Hukum Keluarga di Universitas Chiba Tokyo pinggiran. Selama mempelajari hukum keluarga di Jepang dalam tradisi konfusionis, Murata tertarik dengan Hukum Keluarga Islam yang berkembang dalam tradisi masyarakat Islam.

Ia mendapat beasiswa dari Iran untuk belajar hukum Islam di Universitas Teheran Iran sebagai Negara muslim dengan tradisi dan hukum Islam yang ketat, hal ini tentu akan sangat membantu proses belajarnya dalam mengamati dan mempelajari langsung hukum Islam khususnya hukum keluarga Islam yang menarik minatnya.

Selama masa kulia ia belajar bahasa persia selama 5 tahuan dan menulis desertasi Ph.d dalam sastra persia tentang peranan kaum Wanita. Dimana dalam desertasinya ini ia menggali sastra persia/literatur persia tahun 1971. Kemudian

\footnotetext{
${ }^{3}$ Sachiko Murata, The Tao of Islam: A Sourcebook on Gender Relationship in Islamic Thought, (New York: State Universiti of New York Press, 1992), hal. 327
} 
ia transfer kuliah di fakultas Teologi, dimana ia menjadi satu-satunya perempuan pertama non muslim. ${ }^{4}$

Tutor privat beliau adalah Sayyid Hasan Iftikharzada Sabziwari, terididik dalam metodologi tradisional. Diajarkan menelaah dan mengkaji beberapa teks tersulit dari fiqih dan ushul fiqh disamping bimbingan professor Toshihiko Izutsu. ${ }^{5}$

Tahun 1977 menulis disertasi perbandingan ajaran Islam dan Konghucu tentang keluarga, tetapi terputus karena Revolusi Islam Iran. yang mengantar dia dan suaminya, William Chittick $^{6}$ meninggalkan iran menuju new York, kemudian ia melanjutkan risetnya dalam tradisi intelektual, yaitu upaya memahami pemikiran islam secara mendalam dengan kembali pada teks Al Qur'an dan hadist.

Tahun 1983 menetap di New York dan mengajar di Stony Brook. Department of Comparative Studies, State University of New York Kuliah pertama beliau tentang "Spiritualitas Feminin dalam Agama-agama Dunia".Menjadi direktur pada Japanese Studies yang didirikan sejak 1990 dan aktif mengajar Studi Jepang, Budhisme Jepang, Spiritualitas Feminin dalam agama-agama Dunia dan juga kursus mengenai Islam dan Konfusionisme.

\section{Karya Sachiko Murata}

Buku-Buku Sachiko Murata yang sudah dipublikasikan, antara lain:

a. Izdi waj-i muwaqqat, Teheran Hamdani, 1978, 97 pp;

b. Isuramu hooriran Jestsu (principle of Islamic Law, translation with introduction and commentary of ma'alim al-usiul by Shaykh hasan, Tokyo: Iwanami (Islamic Classiics, general editor T. Isutzu, 1985, 564 pp.

c. Temporary marriage in Islamic Law, London: Muhammadi Trust, 1987, 73 pp, reprinted qum: Ansariyan Publications, 1991.

d. The Tao of Islam: A Sourcebook on Gender Relationship in Islamic Thought, Albany: SUNY Press, 1992, 410pp. Indonesian translation by Ratna Megawangi, Bandung, Mizan, 1995.

e. Sachiko Murata and William C. Chittick, The Vision of Islam, New York: Paragon, 1994, 39+368 pp. Pakistan edition: Lahore: Suhail Academy, 1998.

f. Chinese Gleams of Sufi Light: Wang Tai-yu's Great Learning of The Pure and Real liu Chih's Displaying The Concealment of The Real Realm, Albany: SUNY Press, in production (2000).

Artikel-artikel yang telah ditulisnya, antara lain:

a. Shiaha isuramu no tokushoku ("characteristic of Shi'ite Islam), Isuramu Pawa no Kenkyu, vol. 2, Tokyo: Chutoo Choosakai, 1982, pp.

${ }^{4}$ Ayatullah khu’i merupakan murid Ayatullah sistani yang terkenal sangat konservatif dan salah satu marja' dalam mashab syi'ah

5 Professor Toshihiko Izutsu terkenal sebagai pakar metafisika dan juga tradisi kearifan. Prof Izutsu jugalah yang merintis adanya persamaan antara taoisme dan sufisme.

6 Yang juga mempunyai kemampuan dan keahlian serta focus studi pada bidang yang relative sama. Suaminya, William chittick berkebangsaan amerika merupakan seorang pemikir islam dan mengkaji pemikiran islam/ seorang tradisionalis. 
b. Akund Korasani: His importance in Osul, Encylopedia Iranica, London: Routdge and Kegan Paul, Vol. 1, 1984, pp. 734-35.

c. Anshari, Syaikh, Ibid.., vol. 2, 1985, pp. 102-103. 35

d. Angels on Islmic spirituality: Foundation (vol. 19 of world Spirituality" A Encyclopedia History of the Religions Quest), New York: Crossroad, 1987, pp. 324-344.

e. Masculline / feminine Complementaryin Islamic spiritual Psychology, Islamic Quartely 33, 1989, pp. 165-187.

f. The Tao of Islamic, Sufi 5, 1990, pp. 17-21.

g. Myteries of Marriage: Notes on Sufi Text, the Legacy of Mrdieval Persian Sufism, edited by Leornard.

h. Kawaranu Hito, (The unchanging Personality).

i. Isuramu to Josei (Islam and women).

j. Witnessing the Rose: Ya'qub Sarfi on the vision of God in Women.

k. Ta'lim-1 Islam dar Maghribzamin (Teaching Islam in the West).

\section{Pemikiran Saciko Murata tentang Psikologi Ruhani}

Dalam pembahasannya mengenai psikologi ruhani Murata selalu menghubungkan dengan filsafat taoisme yakni Yin dan Yang dan mengkorespondesikan hubungan anatara manusia, alam dan Tuhan yang ia sebut dengan korespondensi makrokosmos, mikrokosmos dan metakosmos. Manusia adalah merupakan mikrokosmos dari Alam (makrokosmos) dan dibalik keduanya yakni manusia dan alam adalah metakosmos yakni Tuhan. ${ }^{7}$

Sebagai mikrokosmos manusia memiliki hubungan dengan makrokosmos hal ini memungkinkan kita untuk mengetahui gejala-gejala makrokosmik yang mengacu pada manusia. Langit dan bumi, mungkin mengacu pada jiwa dan ruh, atau jiwa dan badan. Posisi fertikal dalam peletakannya menandakan tinggi dan rendah derajat setiap komponen. Misalnya ruh sebagai yang berasal dari Tuhan memiliki kedudukan yang tinggi bila dibanding jiwa yang memiliki bagian dari jasadi, atau jiwa memiliki derajat lebih tinggi karena dia bisa berkorespondensi dengan ruh ketimbang jasadi dan seterusnya.

\section{Struktur Jiwa}

Menurut Murata jiwa manusia terbagi dalam beberapa tingkatan, dan terdiri dari beberapa bagian atau penyebutan yang memiliki sifat yang khas. Dalam analisanya Murata selalu menggunakan simbol yang sering digunakan oleh para sufi untuk menggambarkan kondisi jiwa seorang yang berusaha dekat dengan Tuhan.

\section{Ruh}

Secara khas para sufi mendasarkan penjelasan mereka tentang situasi manusia pada ayat-ayat Alquran dan hadis-hadis Nabi. Ketika membahas tentang Ruh manusia, meraka menaruh perhatian besar pada ayat-ayat yang menyinggung-nyinggung tentang semacam identitas antara ruh manusia dan ruh Ilahi.

\footnotetext{
Sachiko Murata, The Tao of Islam; A sourcebook on Gender Relationship in Islamic Thought, State University of New York Press, 1992, h. 299
} 
Namun apapun bentuknya ruh selalu disebut-sebut dalam setiap penjelasan mengenai penciptaan manusia yang jelas ruh berasal dari Tuhan dan satu-satunya makhluk yang Tuhan ceritakan proses penciptaannya secara mendetail dan khusus hanyalah manusia. Setelah Tuhan menyempurnakan bentuknya maka Dia memberi keistimewaan dengan ditiupkannya ruh-Nya ke dalam ciptaan-Nya tersebut yang kemudian dinamakan manusia. Jadi manusia memng secara fisik memiliki bentuk sempurna dan Tuhan menyempurnakan lagi dengan memberikan manusia Ruh yaitu bagian dari Tuhan. ${ }^{8}$ Inilah nanti yang akan menjadi pembicaraan para sufi mengenai ruh yang ada pada manusia. sebagaimana kutipan berikut ini:

"Makna ganda dari ruh muncul dalam beberapa ayat alquran dimana ruh manusia disebut-sebut, sebab ini semua menjelaskan bahwa apapun bentuk hubungan antara "Ruh Tuhan" dengan Tuhan, ruh ini berasal dari ruh Tuhan sendiri. Alquran membicarakan ruh Tuhan dalam 3 ayat yang dikaitkan dengan penciptaan manusia. Dalam setiap kasus. Tuhan dikatakan membentuk tanah liat Adam, lalu meniupkan sesutu dari ruh-Nya sendiri".

Di sini jelas bahwa ruh berasal dari Tuhan untuk itu para sufi mendudukan ruh pada tingkat yang lebih tinggi dalam semua ciptaannya yakni jasmani. Dalam penciptaan makrokosmos Tuhan menciptakan dua dunia dasar yakni dunia ruhani yang dihuni oleh para malaikan, ruh dan akal dan dunia jasmani yakni dunia materi yang nampak. Begitu juga ketika menciptakan manusia yang disebut oleh para sufi dengan sebutan mikrokosmos, bahwa Tuhan menciptakan manusia terdiri dari 2 subtansi yakni ruh/jiwa dan struktur ragawi. ${ }^{10}$

"Manusia mempunyai suatu dimensi yang terwujud dan dimensi yang tidak terwujud. Dengan kata lain dia mempunyai badan dan ruh. Ruh itu benar-benar sederhana dan tidak dapat dibagi menjadi bagian-bagian ia dimiliki oleh dunia perintah. Badan itu merupakan campuran dan dapat dibagi menjadi bagian-bagian. Ia dimiliki oleh dunia penciptaan."'11

Begitulah Murata memberikan perumpamaan mengenai korespondensi antara ruh dan badan. Dia memberikan perumpamaan pada dunia nyata bahwa ruh itu ibarat langit yang selalu memberi sedang bumi adalah bersifat reseftif atau bersifat menerima. Jadi bisa dikatakan bahwa ruh adalah pengendali jasmani manusia baik atau buruknya yang nampak pada manusia adalah tergantung pada bagaimana ruh itu bisa mengendalikan prilaku manusia tersebut. Ibarat seorang penunggang kuda maka

\footnotetext{
8 Menurut al-Ghazali, yang dikutip oleh Yasir bahwa jism adalah yang tersusun dari unsur-unsur materi. Lihat M.Yasir Nasution, Manusia Menurut Al-Ghazali, (Jakarta; Srigunting, 1988), h. 89. Lihat juga al-Quran Ketika Tuhan menyampaikan kabar kepada para Malaikat bahwa Dia akan menciptakan manusia yang terbuat dari lumpur hitam yang diberi bentuk, lalu Ia akan memberikan ruh ciptaan-Nya. Maka seluruh Malaikat dan Iblis diperintahkan untuk tunduk kepadanya. Surah al-Hijr ayat 28.

9 Sachiko Murata, Ibid., h. 308

${ }^{10}$ Dua subtansi manusia itu terdiri dari jiwa dan raga, namun Tuhan meniupkan ruhn-Nya sebagai penyempurna. Jadi menurut murata ada tiga bagian subtansi manusia. Pembahasan lebih lengkap Lihat d Abdul mujib, Kepribadian dalam Psikologi Islam, Jakarta: Raja Grafindo Persada, 2006, h. 60

${ }^{11}$ Sachiko Murata., h. 311
} 
kemanapun kuda itu berlari adalah tergantung siapa dan bagaimana penungggang kuda tersebut mengendalikannya.

Para sufi mengatakan bahwa tubuh bukanlah bagian dari jiwa. Ia tak lain hanyalah sarana bagi jiwa untuk mendapatkan ilmu dan makrifat tentang penciptaan. Jiwa adalah subtansi maknawi yang berakal dan bukan aksiden. ${ }^{12}$

Jelas sekali bahwa anatara ruh dan jasmani memiliki perbedaan, dan menurut murata perbedaan tersebut terletak pada sifat-sifat yang dimiliki masing-masing. Karena ruh itu berasal dari Tuhan maka ruh memiliki sifat ketuhanan yang lebih kental, sementara jasmani memiliki unsur tanah liat karena dia berasal dari sana. Ruh banyak memiliki pengetahuan sedang jasmani tidak, ruh lebih bercahaya karena dari unsur cahaya sednag jasmani gelap karena berasal dari bumi. Perbedaan kualitas ini sangat jelas karena dua subtansi itu berasal dari sumber yang berbeda.

\section{Jiwa}

Jiwa dilihat dari sifat dan fungsi yang dijalankannya dapat menjadikan jiwa itu berubah nama yang diistilahkan baginya. Jiwa dikatakan roh dalam hubungan kompotitifnya dengan Tuhan, dan dari segi peranannya yang menghidupkan. Jiwa suatu ketika mengandung pemgertian akal karena mampu berfikir dan menyelidiki. Jiwa bisa dinamakan dengan hati atau qalb, karena ia dapat merasakan senang atau susah, baik atau buruk, cinta atau benci. Jiwa mengandung pula pengertian nafs bila dikaitkan dengan dorongan-dorongan yang bersifat khusus atau dorongan-dorongan umum yang ada pada manusia yang bersumber pada naluri atau insting manusia. ${ }^{13}$

Menurut Ibnu Sina jiwa adalah merupakan tabiat yang berbeda dari jasmani dan merupakan hubungan tersendiri, dan hubungan itu mencegah untuk mendapatkan yang rasional murni. ${ }^{14}$ Yang nyata bahwa, jiwa adalah bukan materi dan tidak bisa dianggap sebagai fungsi dari materi. ${ }^{15}$

Menurut Murata para sufi biasanya memandang ruh memiliki kaitan erat dengan Tuhan, sedangkan jiwa atau nafs mewakili manusia. Ruh adalah memiliki tingkatan kosmos yang paling tinggi dibanding jiwa. Ruh terkait dengan prioritas eksistensi sementara jiwa muncul setelah ruh, kalau ruh itu nyata sedang jiwa kurang nyata. Murata sering menggunakan bahasa bahwa jiwa adalah anak ruh karena kemunculannya tergantung ruh.

Ruh bersifat mendominasi karena ia membawa sifat-sifat ilahi untuk dialirkan ke dalam jiwa, seperti sifat-sifat kehidupan, pengetahuan hasrat dan kekuasaan, pembicaraan, pendengaran dan penglihatan. Jiwa bersifat reseptif terhadap sifat-sifat ini dan selanjutnya menjadikannya terwujud melalui badan. Menurut murata hubungan antara ruh dan jiwa adalah hubungan antara pengakuan dan penerimaan.

${ }^{12}$ Ibrahim Hilal, At Tashawnuf al-Ismlami bain ad-Din wa al-Falsafah, diterjemahkan oleh: Idja Suntana, Tasawnf Antara Agama dan Filsafat, (Bandung; Pustaka Hidayah, 2002), h. 145.

${ }^{13}$ Abdul Mias Kabry, Jiwa Keagamaan Membentuk Manusia Seutubnya, (Jakarta; Kalam Mulia, 1993), h. 15-16.

${ }^{14}$ Ibid., h. 15.

${ }^{15}$ Pendapat Ibn Miskawaih, yang dikutip oleh Iqbal dalam Desertasinya, The Development ofMetafbysics in Persia A Contribution to The Historry of Muslim Philosophy diterjemahkan oleh, Joebaar Ayoeh, Metafisika Persia; Suatu Sumbangan untuk Sejarah Filsafat Islam,, (Bandung; Mizan, 1964), cet. ke 3, h. 55 . 
Jadi Murata ingin menggambarkan bagaimana hubungan antara ruh dan jiwa. Melalui gambaran bahwa jiwa adalah istri dan ruh adalah suami. Karena kecenderungan jiwa yang menerima, maka ia diasumsikan sebagai seorang istri, sedang ruh yang cenderung aktif diasumsikan sebagai seorang suami. Ruh menyuburkan jiwa dan jiwa melahirkan aktifitas-aktifitas badaniah di dunia yang terlihat. Ketika ruh yang berasal dari tuhan memberikan perintah kebaika pada jiwa dan jiwa mampu mengaplikasikan kebaikan itu melalui jasmani maka inilah yang dinamakan keselarasan hubungan jiwa dan ruh.

Pelahiran tingkah laku ini dilatarbelakangi oleh adanya dua kebutuhan yaitu, pertama kebutuhan jasmani seperti makan, minum dan sebagainya, kedua kebutuhan rohaniah. ${ }^{16}$

Sebenarnya hubungan ini sangat rumit karena jiwa tidak berdiri sendiri. jiwa sebagaimana yang dikatakan oleh murata adalah merupakan gabungan dari subtansi badani dan ruh, sehingga jiwa memiliki unsur yang tidak sama dengan ruh. Untuk itu ruh sebagai subtansi cahaya memberikan berbagai sifat baik kepeda jiwa agar diaplikasikan melalui struktur jasmani. Disinilah akan terlihat bagaimana manusia bisa mengaplikasikan perintah-perintah dari Tuhan melalui prilaku mereka.

"Begitu ruh dan jiwa hidup dalam keselarasan bagai suami istri, maka masingmasing menjalankan fungsinya dan sesuai dengan hubungan itu . maka dimensi bathin manusia hidup damai dengan realitas paling dalam (Tuhan) dan realitas paling luar (badan). Namun jika perkawinan mereka gagal dan upaya saling mengisi tdk tercapai, mereka tidak dapat memenuhi fungsi-fungsi mereka yang selayaknya". ${ }^{17}$

Menurut Murata, para sufi seringkali menggambarkan jiwa ini sebagai dimensi batin dari manusia yang memiliki kecenderungan negatif. Para sufi membagi tingkatantingkatan jiwa yang kaitannya dengan sifat-sifat yang berbeda: jahat, menyalahkan dan berdamai dengan Tuhan. Maka tidak mengherankan kalo literatur sufi menggunkan defenisi jiwa secara luas untuk mengacu pada jiwa yang menguasai kejahatan dan memiliki ciri-ciri watak yang tercela yang merupakan kebalikan dari ciri dan watak dari ruh. Kalau ruh itu pandai dan baik maka jiwa itu bodoh dan jahat.

Kondisi yang normal antara jiwa adalah siap menerima cahaya-cahaya yang datang dari ruh, dan melalui penerimaan ini jiwa menjadi bercahaya. Jiwa naik dari dunia kegelapan menuju dunia cahay. Kecenderungan turun yang selalu tampil adalah akibat dari ketidakmampuan jiwa untuk melihat cahaya.

\section{Akal}

Akal atau intelengensi ('aql) adalah suatu sifat yang dipuji-puji dalam Alquran dan literatur hadis. Meskipun Alquran tidak menggunakan kata benda itu sendiri, ia menggunakan bentuk verbalnya kira-kira 50 kali. Para penterjemah biasanya menerjemahkan kata kerja itu dengan kata-kata seperti 'memahami', 'berfikir', 'merenungkan', 'melihat', 'membaca', dan lain sebagainya. Akal memungkinkan seseorang untuk menangkap makna penting dari tanda-tanda Tuhan perhatikan bahwa dalam sebuah ayat Alquran menempatkan akal di dalam hati: "Sesungguhnya dalam

\footnotetext{
${ }^{16}$ Zakkiyah Daradjat, Peranan Agama dalam Kesehatan Mental, (Jakarta; Gunung Agung, 1993), h. 32.

${ }^{17}$ Sachiko Murata.,h. 356
} 
penciptaan langit dan bumi dan pergantian siang dan malam ada tanda-tanda bagi orang yang berakal" (QS 2:164)

Menurut Murata akal adalah yang dapat melihat apa yng tersembunyi dan mengungkapkan apa yang tidak diketahui. Dia tidak bisa dipisahkan dari cahaya karena cahaya sebagai penghapus dari kegelapan dan ketidakjelasan. Akal juga dikaitkan dengan sifat-sifat positif lain yang ada hubungannya dengan nama-nama Ilahi Cahaya, seperti kehidupan, hasrat, pengetahuan dan kekuasaan. Dalam kenyataannya cahaya adalah salah satu nama esensi Tuhan maka ia menunjukan peranan Ilahiyah yang sesungguhnya.

'Imam Syi'ah keenam, Ja'far Al-Shadiq mengemukakan sebuah daftar serupa berisi sifat-sifat atau ciri-ciri watak positif yang berkaitan dengan akal, tetapi dia mengkontraskannya dengan sifat-sifat negatif yang berkaitan dengan kebalikan akal, yakni kebodohan (jhil)."18

Para sufiistik selalu mengkaitkan kebaikan akal dengan para nabi yakni yang memberi petunjuk (budan atau Hidayah), yang merupakan sifat Ilahi. Sedangkan sifatsifat kebodohan dikaitkan dengan iblis dan pengikut-pengikutnya. Alquran berulangkali mengingatkan fungsi para Nabi sebagai pembawa petunjuk dan Alquran menyamakan iblis dengan kesesatan sebagaimana firmannya: (QS 28: 15)

Jadi menurut Murata akal yang memiliki sifat-sifat positif akan memberikan petunjuk pada kebahagiaan manusia, sementara kesesatan akan menuntun manusia kesengsaraan. Kedua sifat tersebut sebenarnya memiliki peran yang sama artinyakebaikan dan kesesatan sama-sama membuat potensi tersembunyi manusia bisa terwujud dalam perilaku, walaupun dalam sudut pandang manusia mereka akan membawa pada akhir yang sangat berbeda yakni kesengsaraan dan kebahagiaan.

\section{Hati}

Bagi banyak penulis muslim pengetahuan mengenai hati manusia merupakan kunci menuju pengetahuan tentang Tuhan, makrokosmos, dan mikrokosmos. Hati sebagai jiwa rasional ketika mencapai kesempurnaan merupakan cita-cita dari penciptaan.

Alquran menggunakan istilah Qalb (hati) 132 kali, sementara sinonim-sinonim dekatnya digunakan dalam beberapa kesempatan. Makna dasar dari kata itu adalah membalik, kembali, pergi, maju mundur, berubah, naik turun, pengalami perubahan. Alquran menggunakan istilah hati dlam berbagai pengertian yang semuanya merujuk pada sentralitas hati dalam diri manusia.

Menurut Murata mengapa Alquran menggunakan sinonim, mengalihkan, membalik, mengubah karena hati adalah lokus dari berbagai kebaikan dan kejahatan, kebenaran dan kesalahan. Dan dua kubu itu saling tarik menarik sehingga hati bisa tertarik pada kebaikan atau pada sebaliknya yakni kejahatan.

Bagi para sufi hati adalah bentuk Ilahi dalam diri manusia yang harus dibawa dari potensial menuju aktualitas. Melalui kesempurnaan hati bisa mewujudkan kedua Tangan Tuhan, karena hati merupakan aktualisasi dari dimensi kebaikan dan diensi kejahatan, dimensi cahaya dan dimensi kegelapan.

\footnotetext{
${ }^{18}$ Sachiko Murata, op.cit., h.
} 
Dalam kajian psikologi kesempurnaan hati adalah ketika dia mampu mengaktualisasikan sisi Ilahiat dalam prilaku nyata yang terkonsep dalam asmaul husna. Hal ini oleh Abdul Muzib dinamakan pribadi rabbani yaitu pribadi yang menyerap semua sifat-sifat Ilahi dalam dirinya dan teraktual dalam pribadinya. ${ }^{19}$

Hati adalah cermin yang mampu mnangkap makrifat ketuhanan. Bila cermin itu kotor dan penuh dengan debu serta berkarat maka hati itu akan menjadi suram dan dengan begitu hati tidak bisa menerima cahaya. Agar hati bisa menerima cahaya ia harus selalu dibersihkan dari debu dan karat. ${ }^{20}$

"Dari perspektif perintah penciptaan, Tuhan telah menciptakan hati sebagaimana adanya, barangkali dikuasai oleh petunjuk, atau dikuasai oleh kesesatan. Tetapi dari persfektif perintah petunjuk, hati dianggap mencakup serangkaian sifat positif, seperti petunjuk, iman, akal, pemahaman, cahaya, kepastian, dan seterusnya. Namun dalam kenyataan sesungguhnya hati terperangkap pada kenyataannya sesungguhnya hati terperangkap pada dua sisi cahaya dan kegelapan, ruh dan badan ia mungkin dikuasai oleh jiwa yang menguasai kejahatan dimana ia sepenuhnya gelap. Ia mungkin berdiri di tengah-tengah antara ruh dan jiwa, dimana cahaya dan kegelapan bersaing."

Jelaslah disini bahwa hati menurut Murata adalah salah satu sisi batin manusia. Dia bisa mencapai kesempurnaan karena usahanya untuk selaluh mematuhi perintah ruh, atau selalu mengikuti bisikan-bisikan kebaikan. Namun hati ternyata juga memiliki potensi untuk menjadi lokus yang justru bisa menjerumuskan manusia pada kesesatan hal ini bila hati tidak bisa menahan tarikan-tarikan dari jiwa yang membisikan pada kejahatan dan kesesatan untuk menjauh dari perintah Tuhan.

Pada posisi ini bisa dipastikan bagaimana dimensi batin manusia ketika hati sebagai lokus tidak bisa berdamai dengan ruh yang selalu memberikan kebaikan, maka terjadi ketidakharmonisan dalam batin manusia, dan hal ini akan bisa dilihat perilaku yang akan teraktualisasi dalam kehidupan manusia. Sebagaimana firman Tuhan dalam Alquran surah 7 ayat 201"Sesungguhnya orang-orang yang bertakwa, bila kena rasukan syetan mereka ingat kepada Tuhan dan segera menyadari kesalahan mereka"

Dalam dunia real manusia yang hatinya dekat dengan Tuhan akan cepat mengalami kesadaran bila dia melakukan perbuatan yang melanggar aturan Tuhan. Hal ini akan sangat berbeda dengan manusia yang memang jauh dari kebaikan atau Tuhan, ketika berbuat kejahatan tidak ada kegelisahan dalam hatinya sedikitpun, dan inilah yang disebut Tuhan sebagai mansuia-manusia yang lupa. Sebagaimana firman-Nya surah 82 ayat 6, sebagai berikut;“Hai manusia! Apa yang memperdayamu sehingga kamu durhaka terhadap Tuhanmu Yang Maha Pemurah, yang telah menciptakanmu dan telah menyempurnakan kejadianmu, lalu melestarikan bentuk tubuhmu?"

\section{Hubungan Perilaku dengan Penyucian Jiwa}

Salah satu pemikiran utama para sufi adalah memetakan berbagai tahap atau kedudukan (maqomat) perkembangan ruhani yang dicapai di jalan Tuhan. Pada awalnya diri atau jiwa memiliki sedikit kesamaan dengan ruh yang merupakan nafas Tuhan. Namun karena posisinya diantara kebaikan dan kecenderungan kelupaan,

${ }^{19}$ Abdul Muzib, op.cit., h. 199-216

${ }^{20}$ Laily Mansur, Ajaran dan Teladan Para Sufi, (Jakarta; Srigunting, 2002), h. 162. 
maka peringatan dari Tuhan berupa wahyu untuk memberi petunjuk dan peringatan pada manusia bahwa ia akan selalu berbakti pada Tuhan. Maka untuk merealisasikan pesan tersebut para sufi masuk pada jalan panjang untuk kembali pada seruan Tuhan dan melawan kecenderungan negatif dari jiwa.

\section{Perjuangan Jiwa dalam mensucikan diri}

Sisi bathin manusia memiliki dimensi-dimensi sebagaimana yang telah dibahas di atas yakni jiwa, ruh, akal dan hati, sisi batin inilah yang akan menggambarkan bagaimana perjuangan mansuia sehingga mencapai kesempurnaan batin dan dekat dengan sang Maha Pencipta dan disinilah puncak dari kebahagiaan manusia atau kebahagiaan sejati manusia.

Manusia sebagai mikrokosmik dari alam untuk itu Murata selalu mensinonimkan antara hubungan raga manusia dengan Tuhan dan hubungan antara bumi dan langit. Dalam hal ini murata mengawali dengan dua dimensi ciptaan Tuhan, bahwa Tuhan menciptakan alam ini dengan cara berpasangan, ada siang dan ada malam, ada tangan kanan maka ada tangan kiri, ada kejahatan dan kebaiakan, kebahagiaan an kesengsaraan, ada cahaya dan kegelapan. Untuk itu manusia sebagai mikrokosmik berada diantara keduanya. Begitu juga dimensi batin manusia diposisikan berada diantara dua kecenderungan kebaikan dan keburukan, petunjuk dan kesesatan, malaikat dan iblis, untuk mencapai kebahagiaan seorang sufi harus mampu melawan kecenderungan negatif yang begitu kuat dari jiwa mereka. Kalo mereka mampu melawan kecenderunga negatif maka jiwa-jiwa mereka akan merengkuh kebahagiaan sejati.

Tidak salah bila para sufi beranggapan bahwa nafsu harus ditentang, karena menentang kehendak hawa nafsu merupakan induk ibadah. Al-Halim al Tarmidzi, salah seorang sufi terkenal abad ke $3 \mathrm{H}$ memberikan pengertian tentang jiwa sebagai berikut; Jiwa merupakan bumi sahwat, cenderung kepada syahwat setelah melakukan syahwat, dan harapan setelah melakukan harapan. Jiwa tidak pernah merasa tenang dan diam, perbuatan-perbuatannya selalu berbeda satu dengan yang lainnya. Pada suatu saat berupa 'ubudiyah, pada saat yang lain berupa rububiyah, pada saat yang lain berlaga menyerah, dan pada suatu saat bersifat ingin memiliki. Pada suatu saat bersifat lemah dan disaat yang lain memiliki kekuatan. Namun demikian jika jiwa itu dilatih, niscaya akan dapat diarahkan. ${ }^{21}$

Dalam kajian psikologi nafs dalam tingkatan ini sebagaimana yang dikatakan oleh Han Djumhana, adalah nafs yang mengandung dorongan agresif dan dorongan erotik (birahi), dan bila tidak dikendalikan atau ditundukan maka nafs ini akan menimbulkan kehancuran dan kerusakan, ${ }^{22}$ karena nafs ini berprinsip manyatukan daya amarah

${ }^{21}$ Ami An Najar, Al IlmuAn Nafsi Ash Shufyah,diterjemahan oleh, Hasan Abrori, Ilmu Jiwa dalam Tasawnf, (Jakarta; Pustaka Azzam, 2001), h. 38-39.

${ }^{22}$ Selanjutnya Han Djumhana menyatakan bahwa, nafs mempunyai dua pengertian.. Pertama, nafs yang mengandung dorongan-dorongan agresif (ganas) dan dorongan-dorongan erotik (birahi) yang bisa menjadi sumber malapetaka dan kehancuran bila tak dikendalikan. Nafs dalam arti kedua adalah nafsMutma'innah yang lembut dan tenang serta diundang oleh Tuhan sendiri untuk masuk dalam surga-Nya lihat Han Djumhana Bastaman, Integrasi Psikologi dengan Islam Menuju Psikologi Islami, (Yogyakarta; Pustaka Pelajar, 2001), cet. ke 3, h. 93. 


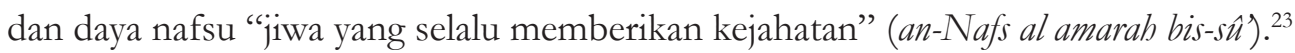
Hal ini akan terjadi bila nafs amarah yang lebih berkuasa maka perbuatan akan lebih condong pada kejahatan.

Dalam terminologi psikologi nafs lebih dikenal dengan sebutan konasi (daya rasa). Konasi kemauan, adalah bereaksi, berbuat, berusaha, berkemauan dan berhendak. Aspek konasi kepribadian ditandai dengan tingkah laku yang bertujuan dan implus untuk berbuat. Nafs menunjukan struktur dibawah sadar dari kepribadian manusia. Apabila manusia mengumbar dominasi nafs-nya, maka kepribadiannya tidak mampu berksistensi baik di dunia maupun di akhirat. Manusia model ini mempunyai kedudukan sama dengan binatang bahkan lebih hina dari binatang. ${ }^{24}$

Berkenaan dengan nafs yang rendah sebagaimana yang dikatakan oleh Mujib bahwa, nafs itu memiliki karasteristik tersendiri diantaranya; pertama, daya-daya (rasa) yang mampu mengindikasi hal-hal yang menyenangkan (syahwat) yang menghindari dari hal-hal membahayakan, daya ini menghasilkan tingkatan irasional. Kedua natur nafs adalah hayawâniyyah (kehewanan) yang dapat menghantar manusia pada tingkat bawah sadar diri kepribadiannya. Seperti gaya hidup hedonisme (serba kenikmatan) gila materi dan seks. ${ }^{25}$

Murata menggambarkan jiwa-jiwa manusia sebagai poros vertikal yang menghubungkan mereka dengan yang Nyata (Tuhan), namun menurut murata hubungan vertikal ini tidaklah tetap (statis) namun bisa berubah-ubah dalam bentuk horizontal, dan pada poros horizontal inilah hubungan itu bisa dikembalikan pada tatanan yang benar melalui perintah.

Menurut Murata keselarasan langit dan bumi, ruh dan jiwa, Tuhan dan kosmos dibangun ketika manusia mencoba untuk menyeimbangkan keselarasan dua nimensi antara jiwa dan ruh, kebaikan dan keburukan, dan untuk menegakan kembali hirarki normatif maka sikap reseptif mereka harus terbuka terhadap petunjuk Ilahi. (331) Jadi untuk mengembalikan batin menuai pada hubungan normatif atau seharusnya, maka sifat menerima harus jiwa harus terbuka, maksudnya jiwa kembali pada sifat aslinya yang menerima perintah kebaikan dari ruh yang notabene berasal dari Tuhan, dan inilah yang dinamakan sifat penyerahan dan penghambaan kepada Tuhan.

Selanjutnya setelah jiwa kembali sifat aslinya yang reseptif maka dia harus berjuang atau bermujahadah dan inilah namanya perang suci yang lebih besar yakni perang melawan nafsu atau kecenderungan jiwa yang negatif. Nabi sendiri mengatakan bahwa musuh terberat adalah nafsunya sendiri.

Hal ini karena jiwa memiliki dua wajah, wajah yang berpaling dari Tuhan harus berserah diri pada-Nya dan wajah yang berpaling dari dunia harus berjuang untuk melawan kekuatan-kekuatan penyesat, untuk menyesatkan kembali jiwa manusia.

${ }^{23}$ Jalaluddin Rahmat, dkk., Menyinari Relung-relung Ruhani, (Jakarta; Ilman dan Hikmah, 2002), cet. 1, h. 36 .

${ }^{24}$ Lihat kembali ayat al-Quran Surah At Tîn ayat 4 dan 5 yang artinya, Sesungguhnya Kami telah menciptakan manusia dalam bentuk yang sebaik-baiknya, Kemudian Kami kembalikan dia ke tempat yang serendah-rendahnya. Menurut terjemahan ini kata rendah diartikan dengan neraka. Lihat Hasbi Ashshidqi, dkk.,op.cit., h. 1076.

${ }^{25}$ Lihat kembali Abdul Mujib, Fitrah dan kepribadian Islam Pendekatan Psikologis, (Jakarta; Darul Falahj, 1999), h. 70. 
Pada umumnya perjuangan untuk menjalin hubungan yang benar digambarkan sebagai sebuah jalan jalan ini mempunyai pendakian yang nampak dan yang tidak nampak, sebab ia menuntun pada aktualisasi kebaikan dan kebajikan dan semakin lama semakin besar, atau kemunculan dari berbagai jenis kegelapan menuju cahaya. Dalam hal ini Alquran memaknai QS 2:257“"Tuhan adalah sahabat bagi mereka yang beriman: Dia membawa mereka dari kegelapan menuju cahaya" dan ayat Alquran lainnya yang artinya; "Inilah kitap yang telah kami turunkan untukmu, agar kamu dapat membawa manusia dari kegelapan menuju cahaya atas izin Tuhanmu" (Qs 14: 1), "Dialah yang memberkatimu, dan malaikat-malaikat-Nya untuk membawamu dari kegelapan menuju cahaya" (QS33:43)

Menurut Murata Tujuan dari perjuangan menuju cahaya itu adalah untuk menegakan keselarasan atau keseimbangan batiniah manusia. Dan keselarasan hubungan antar manusia dipandang sebagai cerminan keselarasan hubungan batiniah manusia itu sendiri.

Jadi ketika manusia itu mampu menjaga keselarasan hubungan diantara manusia dan alam maka disitu merupakan indikasi bahwa kondisi batinnya mempunyai hubungan yang normatif atau jiwanya mengalami kedamaian karena keselarasan hubungan batinnya dengan cahaya Ilahi.

\section{Penyempurnaan Jiwa}

Tujuan hidup manusia adalah menyucikan jiwa dan membiyarkan bergabung lagi dengan dunia cahaya dari mana dia berasal. Dengan mengambil pemikiran Ibnu Sina, Murata berpendapat bahwa kebahagiaan sejati atau menurut Murata kebahagiaan diakhirat dapat kita peroleh dengan membuat jiwa tak tertandingi, berarti menjauhkan jiwa dari kondisi-kondisi badaniah yang bertentangan dengan penyebab kebahagiaan. Namun karena jiwa memiliki dua sifat bawaan yakni kebimbangan dan kemarahan, maka tidak mudah bagi jiwa dalam mensucikan dirinya dari tarikan badania.

Kata kebimbangan (hawa) digunakan secara sinonim di sini dengan nafsu (syahwat). Alquran menggunakannya untuk meringkas seluruh kecenderungan negatif dari jiwa. Mengikuti kebimbangan artinya berpaling dari yang Nyata. Sebagaimana Alquran 23; 71 "Andai kata yang nyata itu harus mengikuti kebimbangan mereka, pasti binasalah langit dan bumi ini beserta isinya"

Fungsi dasar syariat adalah mengalihkan semua kekuatan jiwa ke arah yang akan dapat membantu jiwa untuk meraih kebahagiaan. Sebagaimana Murata mengutip pemikiran Ibnu Arabi bahwa semua indra jiwa dan ciri-ciri watak itu sudah melekat dan tidak dapat dihilangkan. Maka mereka harus diberi arah baru dan inilah fungsi dari petunjuk atau nubuat. ${ }^{26}$

Dari sini jiwa mulai meninggalkan kedudukan yang menguasai kejahatan dan memasuki kedudukan yang penuh perdamaian dengan Tuhan. Ia menjadi sebuah gunung bagi ruh suci. Seperti buraq jiwa akan menyeberangi tempat-tempat persinggahan dan tahap-tahap yang rendah dan tinggi dan mengambil ruh pada tingkatan yang paling tinggi.

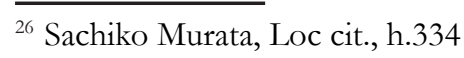


Dengan cara seperti tersebut di atas maka jiwa akan selalu mendapat limpahan dari ruh secara terus menerus. Maka memungkinkan jiwa untuk menerima (reseptif) terhadap perintah ruh yang notabene selalu memerintahkan kebaikan.

\section{Simpulan}

Dari berbagai uraian di atas mengenai pemikiran Sachiko Murata tentang psikologi ruhani maka dapat ditarik beberapa kesimpulan sebagai berikut:

Sachiko Murata menggambarkan secara psikologi, kejiwaan para sufi yang ingin mencapai tahapan tertinggi yakni bersatu dengan Tuhan. Dimana dimensi batin manusia ia gambarkan secara vertikal antara ruh, jiwa (nafs), akal dan hati. Ruh dia gambarkan sebagai dimensi batin yang tertinggi. Ruh memiliki hubungan dengan jiwa, dan jiwa adalah bagian dari jasmani atau struktur ragawi namun jiwa bukan jasmani karena jiwa bisa berhubungan dengan ruh. Hubungan antara jiwa dan ruh memunculkan dimensi batin yang lain yakni akal atau jiwa rasional dan hati. Dimensi batin ini kedudukannya tidaklah statis namun sangat berubah-ubah, karena adanya saling ketertarikan anatara jiwa yang cenderung pada sifat badani dan ruh yang memiliki sifat Ilahiyat. Sangat menarik karena Murata selalu menghubungkan dimensi batin dengan yang dan yin, sifat-sifat maskulin dan feminin.

Perjuangan seorang sufi untuk mencapai tahapan kesempurnaan atau kesucian jiwa ini akan berimbas pada keselarasan hubungan antara dimensi batin manusia secara normatif. Dimana ketika kondisi kembali pada tatanan normatif maka tercapailah kebahagiaan dan kedamaian jiwa manusia yang akan teraplikasi dalam perilaku nyata. Karena dimensi batin manusia mampu mengaktuaisasikan peranan ilahiyat sebagai yang memberikan perintah kebaikan dan petunjuk akan selalu memberikan teguran kepada jiwa-jiwa yang lalai untuk selalu mengingatkan jiwa agar menghadap kembali pada ruh dan siap menerima kebaikan. Inilah yang dikatakan Murata sebagai jiwa yang sehat yakni jiwa yang sangat dipengaruhi oleh ruh atau kebaikan. Jadi jiwa yang sehat akan terlihat dari perilaku manusia yang bisa menjalin hubungan yang baik dengan sesama manusia dan hubungan baik dengan Tuhan.

\section{Daftar Rujukan}

Abdul Mias Kabry, Jiwa Keagamaan Membentuk Manusia Seutubnya, Jakarta; Kalam Mulia, 1993

AbdulMunir Mulkan, Mencari Tuban dan Tujuh Jalan Kebebasan; Sebuah Esai Pemikiran al-Ghazali, Jakarta; Bumi Aksara, 1991

Abdul Mujib, Fitrah dan Kepribadian Islam Pendekatan Psikologis, Jakarta; Darul Falahj, 1999

Abdul Mujib, Dr., H., M.Ag., Kepribadian dalam Psikologi Islam, Jakarta; PT Raja Grafindo Persada, 2006

Al Ghazali, Majmu'ab Rasa'il Al-Imam Al-Ghazali, Jilid 2-6 terj. Irwan Kurniawan, Risalah-risalah Al-Ghazali,Bandung; Pustaka Hidayah, 1994

Amatullah Armstrong, Sufi Terminology (Al-Qamus al-Sufy); The Mystical language of Islam, diterjemahkan oleh Kunci Memasuki Dunia Tasawuf, Bandung; Mizan, 1996 
Ami An Najar, Al IlmuAn Nafsi Ash Shufyah,diterjemahkanoleh Hasan Abrori Ilmu Jiwa dalam Tasawuf, Jakarta; Pustaka Azzam, 2001

Asmaran AS., Pengantar Studi Tasawuf, Jakarta; PT. Raja Grafindo Persada, 2002, cet. Ke 2

Chittick, William C., The Sufi Path of Knowledge; Ibn Al-Arabi Metaphysics of Imagination, diterjemahkan oleh Nidjam M. Sadad Ismail, The Sufi Path of Knowledge; Tuhan Sejati dan Tuban-tuban Palsu,Yogyakarta; Penerbit Qalam, 2001

Chittic,William C., The Sufi Path of Love; The Spiritual Teachings of Rumi, diterjemahan oleh; M. Sadad Ismail dan Ahmad Nidjam, Jalan Cinta Sang Sufi; Ajaran-ajaran Spiritual Jalaluddin Rumi, Yogyakarta; Penerbit Qalam, 2000

Chittik, William C.,Sufism; A Short Introduction, diterjemahkan oleh Zaimul Am, Tasawufdi mata Kaum Sufi, Bandung; Mizan, 2002

Daryanto S.S. Kamus Bahasa Indonesia Lengkap, Surabaya; APOLLO, 1997

Hamka, Tasawuf Perkembangan dan Pemurniannya, Jakarta; Pustaka Panjimas, 1993

Han Djumhana Bastaman, Integrasi Psikologi dengan Islam Menuju Psikologi Islami, Yogyakarta; Pustaka Pelajar, 2001

Ibrahim Hilal, At Tashawnuf al-Ismlami bain ad-Din wa al-Falsafah, diterjemahkan oleh: Ija Suntana, Tasawuf antara Agama dan Filsafat,Bandung; Pustaka Hidayah, 2002

Jalaluddin Rahmat, dkk., Menyinari Relung-relung Rubani,Jakarta; Ilman dan Hikmah, 2002

Jalaluddin Rumi, Fibi Ma Fibi, diterjemahkan oleh Ribut Wahyudi,Inilah Apa Yang Sesunggubnya, Surabaya; Risalah Gusti, 2002

Laily Mansur, Ajaran dan Teladan Para Sufi, Jakarta; Srigunting, 2002.

Lecture,Charles Homer Haskins, A Life of Learning Annemarie Schimmel, diterjemahkan oleh Eva Y. Nukman, Belajar dari Kebidupan Annemarie Schimmel,American Council of Learned Socities, ACLS Occasional paper, No. 21, 1993

Ling,Martin,What's Sufism?,diterjemahkan olehAhkmad,Membedah Tasawuf, Jakarta; Pedoman Ilmu Jaya, 1991

M.Yasir Nasution, Manusia Menurut Al-Ghazali, Jakarta; Srigunting, 1988

Murata,Sachiko, The Tao of Islam; A Sourcebook on Gender Relationship in Islamic Thought, diterjemahan oleh, Rahmani Astuti dan M.S. Nasrullah, The Tao of Islam; Kitab Rujukan tentang Relasi Jender dalam Kosmologi dan Teologi Islam, Bandung; Mizan, 1997

Nicholson,Reynold A., Aspek Ruhaniab Peribadatan Islam, Jakarta; Srigunting, 1997

Peter Salim MA., The Contemporary English Indonesia Dictionary, Jakarta; Modern English Press, 1996

Poewodarminta, Kamus Besar Bahasa Indonesia, Edisi 2, Jakarta; Balai Pustaka, 1995

Schimmel, Annemarie, My Soul is A Woman; The Feminine in Islam terj. Rahmani Astuty, Jiwaku Adalah Wanita; Aspek Feminin dalam Islam, Bandung; Mizan, 1998, cet. I 
Schimmel,Annemarie, Introduction to Islam,diterjemahkan oleh M. Chairul Annam,Islam Interpretatif; Upaya Menyelami Islam dari Inti Ajaran, Aliran-aliran Sampai Realitas Modern, Jakarta; Inisiasi Press, 2003

Schimmel,Annemarie,Mystical Dimension of Islam, terj. Joko Darmono, Dimensi Mistike dalam Islam, Jakarta; Pustaka Firdaus, 2000

Schimmel,Annemarie, My Soul is a Woman; The Feminine in Islam, (New York; The Continuum Publishing Company, 1997

Syaikh Fadhlalla Haeri, The Elements of Sufism, diterjemahkanoleh; Ibn Burdah dan Shohifullah, Yogyakarta; Pustaka Pelajar, 2000

Smith,Margaret,Reading From The Mystics of Islamditerjemahkan oleh Ribut Wahyudi, Mistikus Islam Ajaran-ajaran dan Karyanya, Surabaya; Risalah Gusti, 2001

Victoria Neufelat at al., Webster's New World Dictionary of Amirican English, (New York; Prentice Hall, 1985), h. 990

Yunasril Ali, Manusia Citra Ilabi; Pengembangan konsep Insan kamil Ibn Arabi,oleh al Jili, Jakarta; Paramadinah, 1997

Zakiyah Darajat, Peranan Agama dalam Kesehatan Mental, Jakarta; Gunung Agung, 1993. 